\title{
QUIMBATX, activitats a la carta
}

\author{
Mercè Malgosa i Morera \\ Escola Pia, Terrassa \\ merce.malgosa@escolapia.net
}

Es presenta una estratègia per a ajudar a millorar l'aprenentatge de la química al batxillerat, tenint en compte la diversitat de l'alumnat i la realitat de les aules.

Paraules clau: animacions, TIC, química, batxillerat, $C D$, ritmes d'aprenentatge, diversitat

La meva llarga experiència com a professora de Química d'alumnes de batxillerat em permet analitzar, amb força perspectiva, l'evolució que han patit els alumnes del batxillerat científic i tecnològic al llarg dels darrers anys.

Estic segura que comparteixo amb la majoria de professors d'aquesta matèria de modalitat un cert desencís en constatar dia a dia diversos problemes que fan difícil el seguiment de la matèria per part dels nostres alumnes. És un fet que actualment els nois i noies que arriben al batxillerat ho fan amb perspectives de futur i graus de maduresa força diferents als de fa uns anys. Per altra banda, pretenem que al llarg d'aquests dos cursos de batxillerat els alumnes adquireixin els conceptes, procediments i actituds que els permetin el seu desenvolupament en etapes posteriors, la universitat, els cicles formatius o el món del treball.

Davant d'aquesta situació, podem optar per tres vies ben diferents:

La primera, la més còmoda si més no, és la de fer veure que el problema només és dels nois i noies que tenim al davant. Són ells que s'han d'esforçar per entendre la matèria i treballar més per assolir-ne els objectius. Si no volen o no poden ferho, és el seu problema.

La segona, molt més dràstica, és plantejar-nos canviar de feina. Buscar alternatives en les quals poder desenvolupar els nostres coneixements, que ens permetin sentir-nos més "realitzats" en l'àmbit professional.
Però encara hi ha una tercera possibilitat, que és per la que he optat jo mateixa i segur que també molts de vosaltres, que consisteix a no caure en el parany de mirar enrere i comparar nivells, continguts, actituds... sinó a buscar estratègies que potser no seran la solució per a tots els alumnes, però segur que poden ajudar alguns d'ells a millorar el seu aprofitament de la matèria.

\section{Quins són els principals problemes detectats?}

- D'entrada, la pròpia dificultat de la matèria. En els tres primers cursos de secundària, la química forma part dels crèdits de ciències naturals: només 3 (d'un total de 10). La formació bàsica d'aquesta matèria és, doncs, molt minsa.

- Per altra banda, tot i que s'oferiran crèdits optatius de química en el quart curs de secundària, és ben segur que només una petita part dels alumnes els triaran, com feien fins ara, ja que normalment suposen més dedicació i més esforç que altres crèdits optatius que s'ofereixen en altres matèries. Molts nois no són conscients dels avantatges que aquestes opcions els representarien de cara als batxillerats de ciències; i d'altres, encara no tenen clara l'opció de batxillerat que faran i proven una mica de tot.

- Un altre inconvenient és que no tots els alumnes estan disposats a portar el mateix ritme de treball. Molts d'ells no tenen l'hàbit d'estudi prou assolit i, a part de les bones intencions, no disposen d'eines intel-lectuals suficientment conso- 
lidades. Altres dediquen periòdicament una part considerable del seu temps a activitats extraescolars, esports, idiomes, voluntariat, etc., que no estan disposats a sacrificar.

- L'entrevista personal que fem als nostres alumnes en començar el batxillerat ens mostra perspectives de futur molt diverses: des d'alumnes que tenen molt clar que volen seguir estudis universitaris, medicina, infermeria, veterinària o enginyeria, fins als que prefereixen pensar en algun cicle formatiu, passant per aquells que no tenen clara cap opció o els que estan fent batxillerat per "provar sort" o per recomanació dels seus pares, sense cap motivació ni objectius concrets.

- Davant d'aquest panorama, és complicat disposar de material específic i prou diversificat que ens permeti tenir a mà les activitats adequades per a cada alumne, situació i moment. A més de tot el que podem trobar en el seu llibre de text, si es vol optar per activitats proposades per altres editorials, cal recórrer sovint a fotocòpies addicionals, dossiers de laboratori... és a dir, buscar i improvisar: una inversió de temps considerable per part nostra, i més tenint en compte que molts d'aquests papers és possible que acabin a la paperera!

\section{Per altra banda, ens agradaria que...}

- tots els nostres alumnes fossin capaços d'afrontar la matèria amb garanties suficients per assolir-ne els objectius terminals,

- que poguessin progressar tot i partint de situacions i aptituds diferents,

- amb l'opció d'aprofundir-hi més o menys, segons els seus interessos de futur,

- però fent-la suficientment planera i atractiva com per despertar en ells la curiositat científica,

- i que aprenguin a valorar, criticar, respectar -en fi, a estimar- la química.

\section{Buscant solucions}

- Hem d'insistir més en el fet que el coneixement científic forma part de la cultura en general, desmitificant el paper negatiu que sovint s'assigna a la química i remarcant els aspectes positius amb què contribueix a millorar la nostra societat. Podem proposar els objectius de cada unitat a partir de lectures que els relacionin amb aquestes qüestions.
- És necessari potenciar la comprensió i la simplicitat dels conceptes més que no pas la seva memorització i la seva complexitat, crec que així farem l'assignatura més assequible i aconseguirem més interès per part dels alumnes. S'han de vincular molt més els temes tractats amb aspectes propers, posant exemples del nostre entorn que ells puguin entendre millor.

- Tots sabem que una forma d'engrescar els alumnes és portar-los al laboratori. Per tant, hem de contemplar la possibilitat de fer més activitats pràctiques. Però això suposa disposar d'un conjunt més ampli d'activitats de laboratori amb diferents graus de dificultat i d'aprofundiment.

- Per altra banda, per poder aprendre a resoldre problemes de química amb una certa seguretat és convenient disposar de suficients i variats enunciats per a reforçar o aprofundir els temes.

Totes aquestes consideracions m'han portat, al llarg dels anys, a reunir i a elaborar diversos materials que finalment he recollit sota el títol "QUIMBATX - Activitats a la carta".

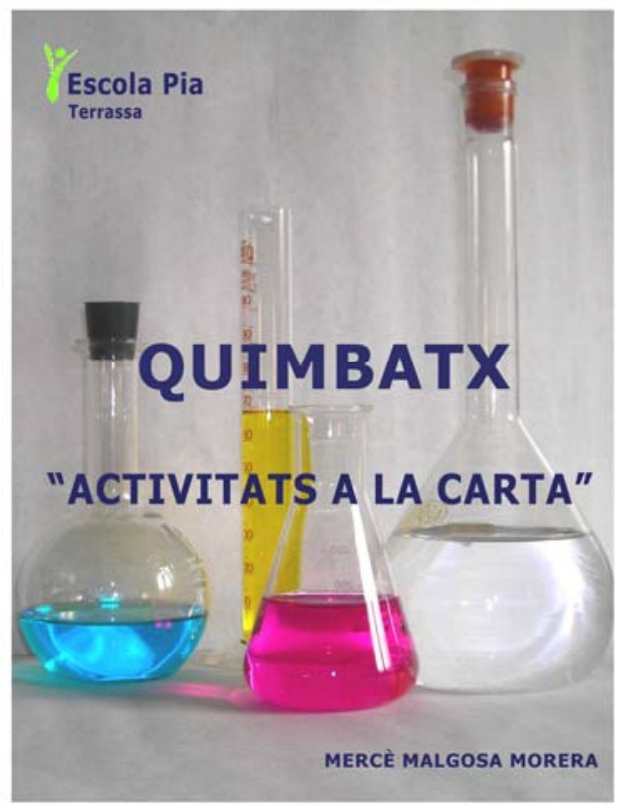

\section{QUIMBATX - "Activitats a la carta"}

QUIMBATX és un material adreçat als alumnes dels batxillerats científic i tecnològic que han optat per la matèria de Química i que per tercer curs consecutiu utilitzem com a suport de la matèria a la nostra escola.

El setembre del 2005, en començar el primer curs de batxillerat, els alumnes de química varen rebre un CD amb un recull d'activitats de laboratori i de qüestions i problemes, relacionats amb els diferents temes que es tractarien a la matèria durant 
els dos anys de batxillerat. En començar el curs 2006-2007 ja s'hi havien incorporat, a més, algunes de les lectures introductòries dels temes.

Enguany s'hi ha afegit la part anomenada Eines, encara que no de forma completa.

La idea és que a partir del proper curs aquest material estigui a disposició dels alumnes a la Plataforma Educativa Virtual del Centre.

Per a utilitzar aquest material, els alumnes han de conèixer el seu contingut general i la forma de treballar els diferents tipus d'activitats que conté. Per això dediquem una de les primeres sessions del curs a la presentació i manipulació del QUIMBATX a l'aula d'informàtica.

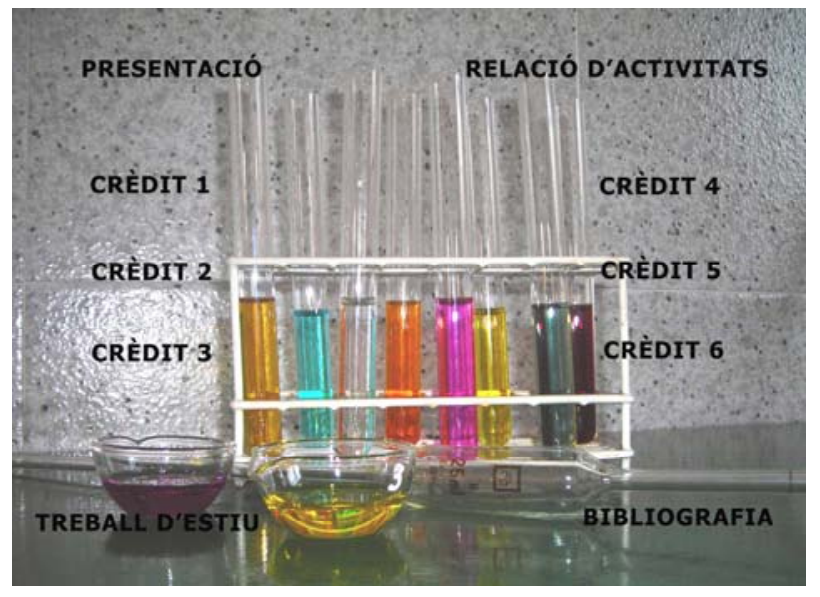

\section{Crèdits, unitats i apartats}

En la Presentació s'expliquen els objectius d'aquest material i com està estructurat el contingut de química dins del $C D$, doncs no coincideix exactament amb la distribució que en fan els llibres de text de batxillerat, ja què en aquests apareixen alguns temes duplicats a $1 \mathrm{r}$ i a $2 \mathrm{n}$, pel diferent grau d'aprofundiment que se'n fa; cosa que en el CD no té sentit ja que aquesta qüestió és precisament un dels principals objectius amb què s'han elaborat aquestes activitats.

Es donen també, en aquest apartat, Consells per a l'aprofitament i Normes per a la seguretat al laboratori, en què es valora el risc potencial del treball experimental i es pretén fer conscient l'alumnat que les actituds que s'han de potenciar al laboratori són la responsabilitat i la prudència, i que tots han de conèixer i complir les normes de seguretat sense excepcions.

També s'hi inclouen els Pictogrames de perillositat amb les recomanacions pertinents, consells generals per a les Llibretes de laboratori i per a l'elaboració dels Informes de les activitats experi- mentals i les Instruccions generals per a la manipulació del CD amb el llistat de totes les unitats i les seves icones.

S'explica on hi ha els Enllaços per a cadascun dels sis crèdits en què està distribuïda la matèria que, més o menys, corresponen a tres per al primer curs i tres per al segon. Però tenint en compte la diversitat d'activitats i els diferents nivells de dificultat, poden aprofitar-se en diferents moments al llarg dels dos cursos.

Cada crèdit conté quatre unitats, excepte els dos últims que només en tenen tres, fent un total de vint-i-dues unitats.

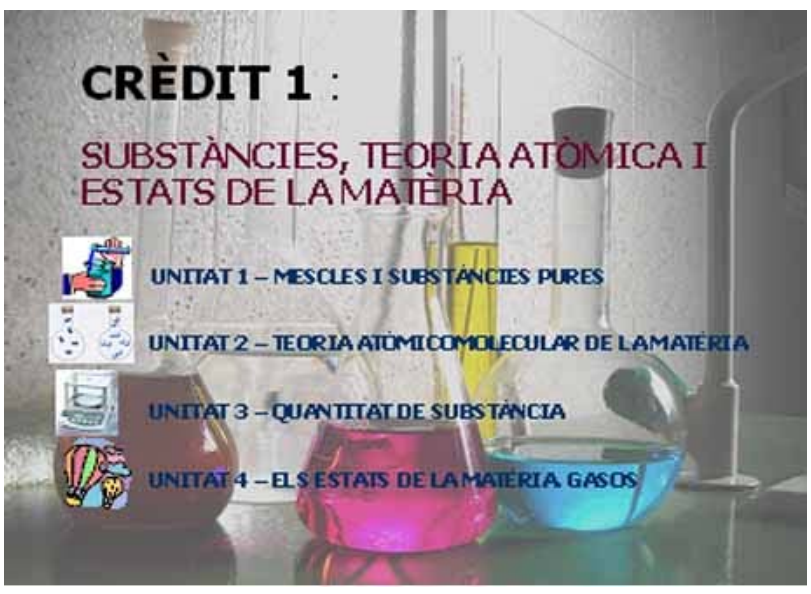

Cada unitat va associada a una icona, relacionada amb algun dels aspectes que es tracten. Totes les activitats d'aquesta unitat porten la mateixa icona identificadora vinculada als diferents tipus d'activitats proposades per a cada unitat del crèdit.

Per exemple, el Crèdit 1, al qual hem assignat el títol general de "Substàncies, teoria atòmica i estats de la matèria", comprèn les unitats següents:

- Unitat 1: Mescles i substàncies pures

- Unitat 2: Teoria atomicomolecular de la matèria

- Unitat 3: Quantitat de substància

- Unitat 4: Els estats de la matèria. Gasos

Cadascuna apareix amb la icona corresponent, que permet accedir a cada unitat.

Dins de cada unitat hi trobem els diferents materials que s'hi ofereixen. Per exemple en el Crèdit 1, a la primera unitat, que és Mescles i substàncies pures, les Activitats proposades són: 


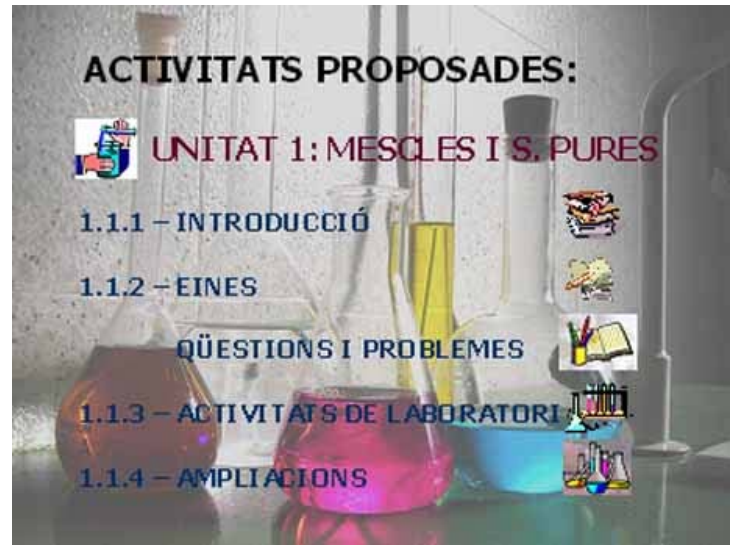

Les icones que apareixen a cada tipus d'activitat estan vinculades als arxius corresponents i són les mateixes per a totes unitats; és a dir, a totes les unitats hi ha una introducció, lectures, eines, les qüestions i problemes, les activitats bàsiques de laboratori i les ampliacions. Cada unitat amb la seva icona identificadora.

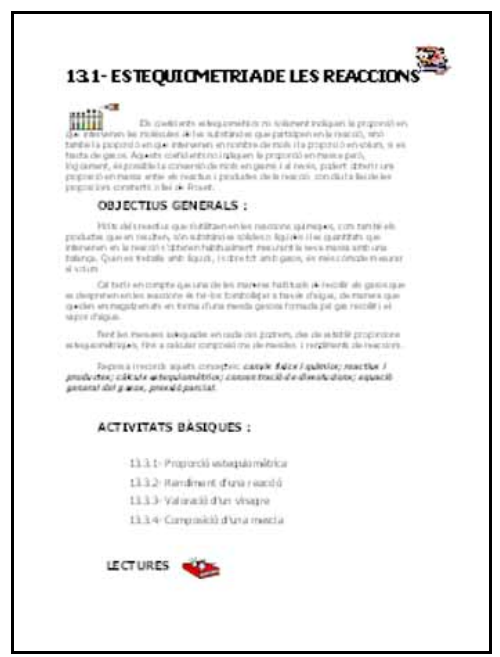

La Introducció de cada unitat comença amb un pròleg per motivar l'interès dels alumnes vers el tema en concret i en justifica l'aprofundiment, relacionant aquella unitat amb aspectes de la nostra societat o amb aplicacions industrials senzilles, que ells puguin comprendre. També especifica quins són els objectius generals de les activitats de laboratori que es proposen en aquella unitat i quins els conceptes teòrics que hi estan relacionats i que treballaran a classe.

També hi trobaran l'índex de les activitats bàsiques de laboratori d'aquella unitat.

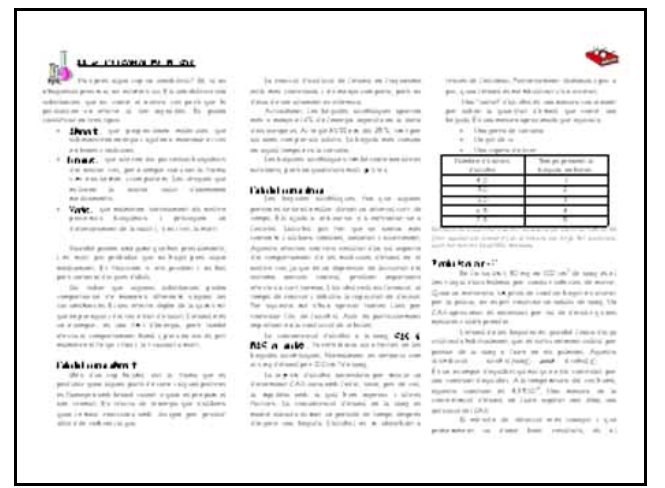

Finalment, es proposen algunes Lectures relacionades que, segons el casos i el temps que puguem dedicar-hi, es llegiran a classe o es recomanaran com a feina complementària.

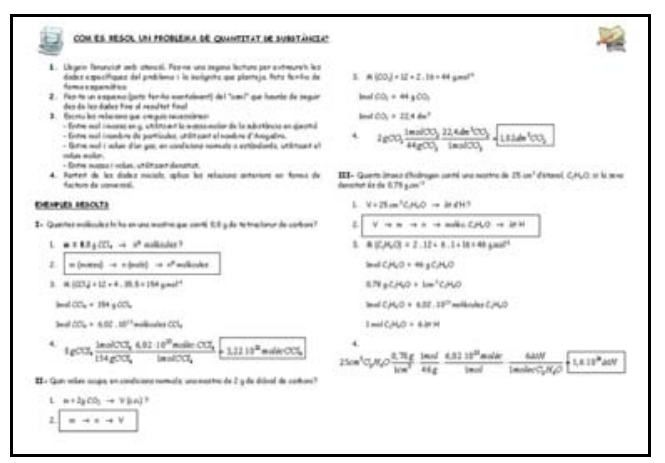

Les Eines proposen estratègies per a la resolució de problemes del tema amb exemples ja resolts.

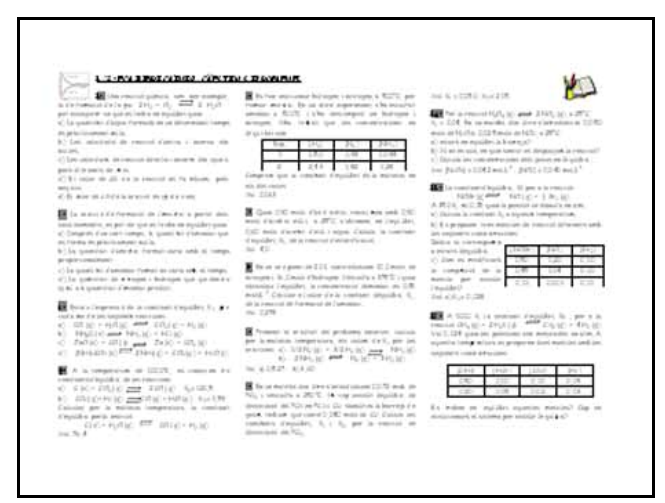

Les Qüestions i problemes són un recull d'enunciats diferents dels del seu llibre de text, amb formats i graus de dificultat diversos. Poden ser de reforç, de recuperació o d'ampliació.

La majoria d'aquestes qüestions i problemes no es treballen ni es corregeixen a classe, sinó que es proposen com a feines més o menys optatives, segons les necessitats dels alumnes: per a preparar 
controls, com a reforç per a recuperar avaluacions no superades... Els alumnes les Iliuren en els moments establerts, es retornen corregides i es valoren adequadament en cada cas.

Les Activitats de laboratori són aquelles experiències que es consideren bàsiques, és a dir, les que estan més directament relacionades amb els continguts específics de cada unitat i són les que tots els alumnes haurien de realitzar al llarg del batxillerat, atenent però a les particularitats de cada grup d'alumnes en concret.

En cada activitat s'especifica:

- Els objectius i els fonaments de l'experiència.

- El materials i els productes necessaris per portar-la a terme.

- El procediment pràctic, és a dir, el guió que han de seguir. En les sessions assignades, els alumnes han de portar, impreses en paper, les activitats corresponents, per poder fer les experiències al laboratori.

- I, finalment, han de respondre o deduir les qüestions, càlculs i conclusions plantejats en la part final de l'activitat, que es recullen, s'avaluen convenientment i es retornen als alumnes.

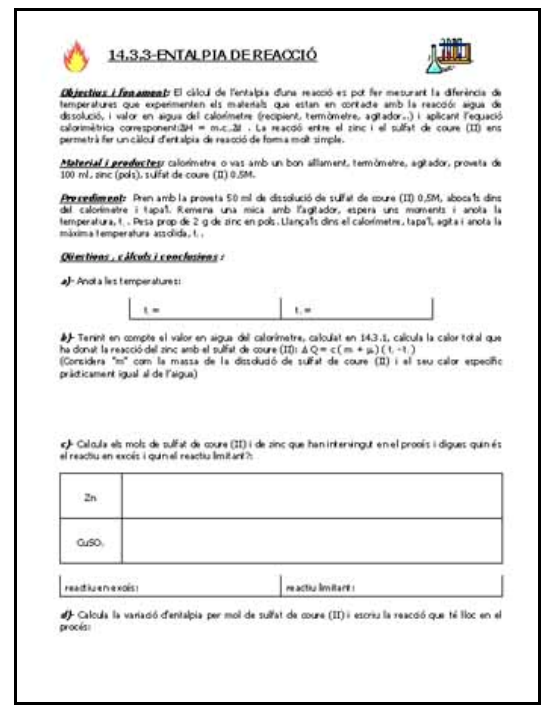

No tots els alumnes fan les mateixes activitats simultàniament sinó que es distribueixen en grups de dos i treballen de forma independent uns dels altres, permetent d'aquesta manera diferents ritmes.

L'actitud en les feines de laboratori, el nombre d'activitats realitzades i el rigor amb què s'han fet les experiències i amb què s'han contestat les qüestions, queden reflectits en la nota de l'avaluació corresponent.
Però és en les Ampliacions on realment es posa de manifest el diferent ritme de treball dels alumnes. Les activitats d'ampliació són opcionals, però es recomana que en facin "algunes" al llarg del curs. L'alumne pot escollir les ampliacions que li resultin més engrescadores.

En aquestes activitats d'ampliació els procediments pràctics estan menys detallats, ja que alguns s'hauran treballat anteriorment i d'altres es poden considerar d'un nivell d'aprofundiment més gran, de més dificultat, que només tenen sentit com a complement d'una activitat anterior.

En aquestes activitats se'ls fa elaborar un informe, en lloc de demanar qüestions concretes.

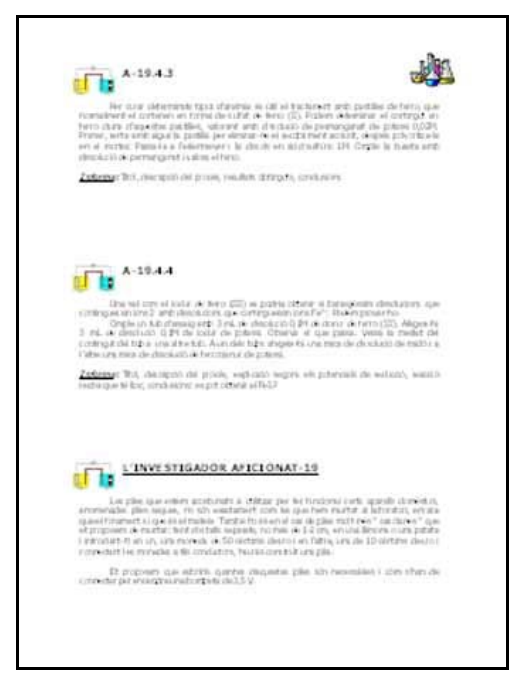

Les ampliacions les poden fer en les sessions de laboratori només aquells alumnes que porten un ritme de treball superior, i sempre que no interfereixin amb les activitats bàsiques. Però també se'ls ofereix la possibilitat de treballar al laboratori en altres moments, fora de l'horari escolar, com els dimecres a la tarda, que no tenen classe. Algunes d'aquestes activitats les poden fer, fins i tot, a casa.

Finalment, l'apartat L'investigador aficionat que s'ofereix al final de cada unitat, planteja una qüestió i suggereix als alumnes que dissenyin el procés pràctic a seguir per a resoldre-la. Cada alumne pot posar de manifest la seva perspicàcia, desenvolupar la seva imaginació i evidenciar el seu mètode científic.

\section{Altres enllaços}

La pàgina principal també esta vinculada a:

- Una Relació d'activitats de laboratori en la qual s'especifiquen totes les experiències: tant les 
bàsiques com les d'ampliació per a cadascuna de les 22 unitats. En total el QUIMBATX conté 75 activitats bàsiques, 70 activitats d'ampliació i 22 propostes d'investigació.

- El Treball d'estiu recull un conjunt de qüestions i problemes addicionals sobre els continguts treballats al primer curs de Batxillerat. Està pensat perquè aquells alumnes que en acabar el primer curs no han aprovat la matèria puguin prepararse millor per a l'avaluació de neteja, i també perquè els que ho han fet amb dificultats, puguin començar el segon curs amb una millor preparació.

- La Bibliografia consultada per a l'elaboració d'aquest material.

Amb tot el material que han tret del QUIMBATX i totes les feines que han fet a partir d'ell, els alumnes han d'anar elaborant un dossier i presentar-lo a final de curs, convenientment ordenat, de manera que pugui ser avaluat de forma global i incidir en la nota final de la matèria.

En aquests moments, el QUIMBATX conté 20 Lectures, 6 Eines per a la resolució de problemes,
492 Qüestions $i$ problemes, 60 més a Treball d'estiu, 75 Activitats bàsiques de laboratori, 70 Activitats d'ampliació i 22 Propostes d'Investigació.

\section{Què queda per fer?}

- S'ha d'acabar de completar la part de les lectures que falten en alguna de les unitats. També serà necessari actualitzar-les cada nou curs.

- També s'afegiran eines de resolució de problemes en algunes de les unitats.

- S'introduirà també un apartat amb esquemes o resums del contingut de cada unitat que puguin servir de repàs de cara a preparar controls de la matèria o les PAU.

- Exemples de proves de selectivitat d'altres anys i d'altres comunitats.

- Relació d'adreces, amb els vincles corresponents, que considerem interessants per a complementar i aprofundir en diversos aspectes.

Quedar clar, doncs, que QUIMBATX, Activitats a la carta, no és un material tancat. El seu contingut està sotmès a revisions periòdiques que permeten noves incorporacions i millores. 